\title{
Cortisol and 3,4-Methylenedioxymethamphetamine: Neurohormonal Aspects of Bioenergetic Stress in Ecstasy Users
}

\author{
A.C. Parrott \\ Department of Psychology, Swansea University, Swansea, UK
}

\section{Key Words}

3,4-Methylenedioxymethamphetamine - Ecstasy •

Cortisol $\cdot$ Hormone $\cdot$ Stress $\cdot$ Energy $\cdot$ Cognition

\begin{abstract}
Aims: 3,4-Methylenedioxymethamphetamine (MDMA) can affect both neurotransmitter and neurohormonal activity. This review will debate the role of the metabolic activation hormone cortisol for the psychobiological effects of ecstasy/ MDMA. Methods: The empirical literature on cortisol release following acute MDMA administration and cortisol functioning in drug-free recreational ecstasy/MDMA users will be reviewed. This will be followed by an overview of cortisol as a bioenergetic stress neurohormone, and a debate on how it could be modulating the acute and chronic psychobiological effects of MDMA. Results: Cortisol release is increased by stimulatory factors, including physical activity, thermal stress and stimulant drugs. In laboratory studies MDMA leads to an acute cortisol increase of around $150 \%$ in sedentary humans. In MDMA-using dance clubbers, the cortisol levels are increased by around $800 \%$, possibly due to the combined factors of stimulant drug, physical exertion and psychosocial stimulation. Regular ecstasy/MDMA users also demonstrate changes in baseline cortisol levels and cortisol reactivity, with compromised hypothalamic-pituitary-adrenal activity. Nonpharmacological research has shown how
\end{abstract}

cortisol is important for psychological aspects such as memory, cognition, sleep, impulsivity, depression and neuronal damage. These same functions are often impaired in recreational ecstasy/MDMA users, and cortisol may be an important modulatory co-factor. Conclusions: The energizing hormone cortisol is involved in the psychobiology of MDMA, probably via its effects on energy metabolism. Acute cortisol release may potentiate the stimulating effects of MDMA in dance clubbers. Chronically, cortisol may contribute to the variance in functional and structural consequences of repeated ecstasy usage.

Copyright $\odot 2009$ S. Karger AG, Basel

\section{3,4-Methylenedioxymethamphetamine: Neuropsychobiological Overview}

3,4-Methylenedioxymethamphetamine (MDMA) is a powerful indirect agonist for serotonin and dopamine, and it also affects noradrenaline, acetylcholine and histamine [1-3]. It is widely used as a recreational drug under its street name of 'ecstasy' [4-6]. Acute MDMA is a powerful central nervous system stimulant, and the marked psychophysiological stimulation can lead to a range of problems, including mental confusion, physical exhaustion and some potentially dangerous medical complications [7-9]. In chronic terms, the regular use of

\section{KARGER \\ Fax +4161306 1234 \\ E-Mail karger@karger.ch}

www.karger.com

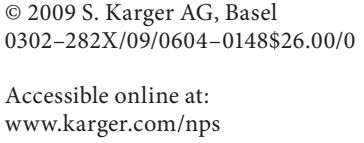

Prof. A.C. Parrott

Department of Psychology

Swansea University

Swansea SA2 8PP (UK)

Tel. +44 1792295 271, E-Mail a.c.parrott@swansea.ac.uk 
MDMA is associated with structural changes and functional deficits. In laboratory rats, monkeys and primates, MDMA is a serotonergic neurotoxin [1-3], and the extent of neuronal damage is heightened by environmental conditions which increase the energy expenditure [1, 10-12]. In humans neurotoxicity has been investigated using various neuroimaging procedures, including PET, EEG, MRI and fMRI [13-17]. In a comprehensive review, Cowan [13] concluded that the most robust finding was a reduction in serotonin transporter density, although variance in the neuroimaging data was also noted.

The first functional deficits to be demonstrated in recreational ecstasy/MDMA users were memory problems [18], and deficits in various aspects of memory and cognition have been confirmed in many subsequent studies [19-30]. Prospectively, the continued use of ecstasy/ MDMA leads to more memory deficits, while drug cessation stabilizes or partially reverses them $[31,32]$. Functional deficits also occur in other areas of cognition, sleep, sex, psychiatric well-being, event-related potentials, immunocompetence and oxidative stress [27, 28, 30, 33-52]. Although, as with the structural data, there is variance in the functional findings, with several factors influencing their occurrence [review: 53]. Lifetime ecstasy consumption is important, with novice/light ecstasy users typically showing normal functioning, moderate users having some impairments and heavy users displaying numerous deficits [33-35, 49-50, 54-59; also 22, 24, 56]. Another important co-factor is the use of other psychoactive drugs, including alcohol, amphetamine, cannabis, cocaine and nicotine $[8,19,20,26,27,29,30,34,40,43$, $60-68]$. Hence it is important to note that the functional deficits of recreational Ecstasy/MDMA polydrug users often remain significant, after controlling for the influence of other recreational drugs $[8,19,21,25,26,30,33$, $39,40,46,53,61,69,70]$. However the cognitive profiles of these polydrug users will reflect the influence of multiple compounds. For instance, cannabis is strongly associated with everyday memory problems, whereas MDMA is more linked with prospective memory problems and deficits in delayed recall $[20,122]$ so that users of both drugs can display a range of neurocognitive deficits $[20,25,53,69]$. Environmental and physical factors such as temperature, crowding and prolonged dancing may also influence the psychobiological effects of MDMA [reviews: 10, 53]. These multiple drug and nondrug influences have been integrated into a general bio-energetic stress model. This model will now be outlined, before the contributory role of cortisol is debated.

Cortisol and

3,4-Methylenedioxymethamphetamine

\section{Bioenergetic Stress Model for Recreational Ecstasy/MDMA}

The bioenergetic stress model for recreational ecstasy $[7,53,71]$ was based on an earlier animal model [10]. This model noted that MDMA was a powerful central nervous system stimulant and metabolic stressor, and these effects were increased by stimulant co-factors such as heat and crowding. For instance, MDMA is more damaging to laboratory animals when administered at high ambient temperatures $[10,11]$. In humans, the multiple stimulatory factors at dance clubs can lead to high levels of bioenergetic stress. Most recreational ecstasy-using dance clubbers develop a mild 'serotonin syndrome', with tachycardia, hyperkinesia (excessive-repetitive movements), thermal stress and mental confusion [7, 72]. A minority develop stronger signs of overheating and physical exhaustion $[9,71]$. The energetic stress model proposes that the regular experience of these periods of hyperstimulation, will cumulatively lead to more chronic bioenergetic distress [53] and the multiple psychobiological problems of many heavy Ecstasy users [23, 48, 50, 53]. Darvesh and Gudelsky [73] similarly noted that 'MDMA produces a dysregulation of energy metabolism which contributes to the mechanism of MDMA induced neurotoxicity'.

Cortisol is important for normal metabolic activation and for energy mobilization under physically demanding situations $[74,75]$. Cortisol may therefore have an important role in the bioenergetic stress model of MDMA. Since MDMA-induced serotonergic effects stimulate the hypothalamo-pituitary-adrenal (HPA) axis, leading to an increase in cortisol levels, cortisol may be involved in the energy mobilization following acute ecstasy/MDMA. In chronic terms, cortisol plays a role in many core psychobiological functions, including memory, sleep, appetite, psychiatric symptoms and neuronal damage. The preliminary aim of this article will be to empirically review how cortisol influences the psychobiological effects of MDMA. The final section will propose a theoretical integration, by suggesting that cortisol can have an important contributory role for the bioenergetic stress model of recreational ecstasy/MDMA.

\section{Cortisol Psychobiology}

Selye [74] noted that cortisol was important for homeostasis and psychobiological integrity, particularly under conditions of high energy demand. Cannon [76] had demonstrated how a stable internal physiological en-

Neuropsychobiology 2009;60:148-158 
vironment was achieved through internal feedback systems which react to environmental changes. Cannon had also noted that achieving homeostasis involved 'stresses and strains'. Selye [74] focused on this aspect of homeostasis by investigating the psychobiological reactions to physically demanding situations. Selye noted that when the body was pushed to its physical limits, its capacity for metabolic activation was in danger of being overloaded. Under these circumstances a 'general adaptation syndrome' came into play. This comprised an integrated set of neurohormonal and physiological reactions (next paragraph), which provided additional metabolic resources - and enabled the organism to cope. Selye's [74] research was based on physical stressors, such as extremes of heat or cold and prolonged periods of muscular activity in athletes. The physical background to the concept of stress is reflected in terms such as 'feeling overloaded', 'under pressure', 'being stretched' and 'having a breakdown'. These mechanical terms are taken from testing the physical limits of industrial machines.

The nervous system circuitry involved in cortisol release has been summarized by Lovallo [75, p. 48]: 'In response to states of emergency, the hypothalamus secretes corticotropin releasing factor (CRF) in to the specialized portal circulation of the pituitary stalk, where it travels to the anterior pituitary, causing the release of adrenocorticotropin and beta endorphin into general circulation. Adrenocorticotropin travels to the adrenal cortex, where it causes a dramatic increase in the rate of production and secretion of the glucocorticoid hormone cortisol. Cortisol is capable of affecting every major organ system in the body and it is essential for the maintenance of normal organic and metabolic functions [77]. Cortisol's importance is indicated by the fact that it assists in many normal functions during both normal activity and stressful periods'. Herbert et al. [78] noted that cortisol was important for many aspects of homeostasis, both predictive and reactive. Predictive homeostasis is based on circadian rhythms, with cortisol being involved in the daily rhythms of rest, activity and sleep. The release of cortisol follows a well-established circadian pattern, with a peak 1-2 h after waking, followed by a rapid decline, and stabilization 3-4 h after waking with constant levels over the rest of the day $[79,80]$. These circadian rhythms are controlled through the suprachiasmatic nucleus or hypothalamic 'clock'. They tend to be consistent for each individual but vary between people, with this variation being linked with propensity for stress [75]. Cortisol is one of the most labile and reactive of all neurohormones [78], since its release is also stimulated by physical or psycho- logical stressors. During this 'reactive' homeostasis, cortisol stimulates the sympathetic nervous system, increases catecholamine synthesis, releases stored glucose and lipids, and suppresses immunoreactivity [75]. This prepares the body for energy expenditure and physical activity. Hence cortisol is important for both everyday metabolic activation and for energizing bodily resources when coping with novel demands.

\section{MDMA Effects on Cortisol}

Dumont and Verkes [81] reviewed the effects of acute MDMA in human laboratory research. They noted that 12 placebo-controlled studies had assessed cortisol, with 11 reporting significant increases and the twelfth finding a nonsignificant trend after a low dose. Mas et al. [82] found significant cortisol increases after 75 and $125 \mathrm{mg}$ oral MDMA, which peaked around $2 \mathrm{~h}$ after administration. De la Torre et al. [83] similarly reported that 3 dose levels of oral MDMA (75, 100 and $125 \mathrm{mg})$ led to significant increases in plasma cortisol in human volunteers, which again peaked $2 \mathrm{~h}$ after administration. Pacifici et al. [42] observed a significant increase in cortisol following $100 \mathrm{mg}$ oral MDMA, which was similar to their earlier findings [41]. They also investigated the effects of 2 closely spaced doses of MDMA and found the cortisol increase following the second dose was similar in magnitude to the first [42]. Harris et al. [84] reported that 0.5 $\mathrm{mg} / \mathrm{kg}$ MDMA led to an increase over baseline of around $100 \%$, while $1.5 \mathrm{mg} / \mathrm{kg}$ MDMA caused a percentage increase of around $150 \%$ over baseline. These and other findings allowed Dumont and Verkes [81] to conclude that in the laboratory, acute doses of MDMA led to a 'robust' increase in cortisol.

Cortisol has also been investigated in 2 prospective studies of recreational users at dance clubs and house parties. The ecstasy users were assessed on successive weekends when clubbing or partying on-ecstasy as usual and when completely abstaining from MDMA or other stimulant drugs. The first study involved dance clubbers, with saliva analyses confirming the presence of MDMA during the on-drug weekend and its absence during abstinence [64]. Dance clubbing on ecstasy/MDMA led to an $800 \%$ group increase in saliva cortisol, significantly higher than both baseline and dance clubbing during abstinence (fig. 1). The second study involved a very similar design, with experienced ecstasy users at a house party. At baseline the group mean cortisol level was $0.3 \mathrm{mg} / \mathrm{dl}$; this increased to $1.0 \mathrm{mg} / \mathrm{dl}$ after $2 \mathrm{~h}, 2.3 \mathrm{mg} / \mathrm{dl}$ at $4 \mathrm{~h}$ and 
$1.5 \mathrm{mg} / \mathrm{dl}$ after $6 \mathrm{~h}$. The cortisol levels while partying without MDMA remained statistically unchanged at around $0.3-0.5 \mathrm{mg} / \mathrm{dl}$. Hence this second study also found a similar peak cortisol increase of around $800 \%$ in weekend party goers after taking MDMA [85].

Cortisol is therefore increased by $150 \%$ in the laboratory [84] and by $800 \%$ in recreational ecstasy users [64]. This may reflect the combined effects of stimulant drug and environmental factors such as loud music, prolonged dancing and social crowding. Alternatively it might reflect other factors such as greater self-dosing or circadian aspects (greater sensitivity at night?). Another potential factor is the MDMA-induced psychophysiological and metabolic changes. Herbert et al. [78] noted that 'perturbation of the internal environments which challenge homeostasis, such as lack of food, water, salt or excessive temperatures, all elicit increased corticosteroid secretion as part of the response to such demands or stressors'. Many of these changes may be occurring in dance clubbers. Hence it is important to note the largely unchanged cortisol levels in dance clubbers and party goers when abstaining from MDMA [64, 85; fig. 1]. These psychophysiological and metabolic factors may however still be important when on MDMA. Whatever the amalgam of causal factors, the cortisol values indicate a very high level of neurohormonal activation in recreational MDMA users (fig. 1).

In chronic terms, recreational ecstasy users show changes in cortisol reactivity. Gerra et al. [86] reported a significantly reduced cortisol response to a d-fenfluramine challenge in drug-free recreational MDMA users. Verkes et al. [27] found reduced cortisol responses to dfenfluramine in 2 groups of moderate and heavy ecstasy users. Crucially, their control group comprised non-ecstasy users who were regular dancers and ravers, hence controlling for the environmental factors of dancing and clubbing (previous paragraph). Their group differences in cortisol reactivity also remained significant after controlling for several potential confounds. Gerra et al. [87] replicated their earlier finding of a reduced cortisol response to a d-fenfluramine challenge. Gerra et al. [88] noted that the baseline cortisol levels were significantly lower in drug-free ecstasy users compared to controls, along with significantly reduced cortisol responses to a psychosocial stressor. The authors concluded: 'HPA basal hyperactivation and reduced responsiveness to stress, may represent a complex neuroendocrine dysfunction associated with MDMA use.'

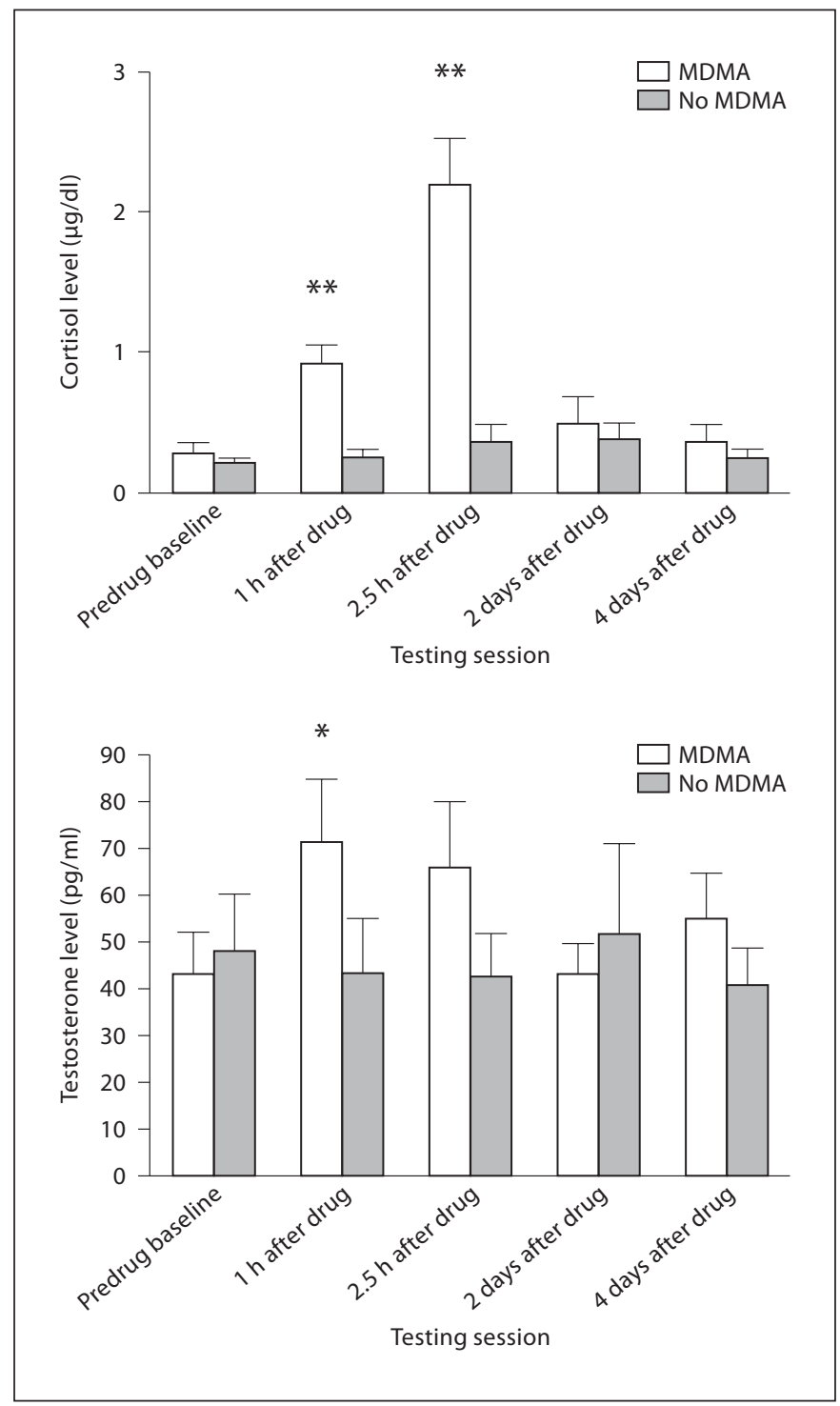

Fig. 1. Cortisol and testosterone levels for 12 recreational ecstasy/ MDMA users before, during and after dance clubbing (means and standard errors). Each participant was assessed on self-administered MDMA and off MDMA, over counterbalanced weekends at the same dance club. MDMA presence was confirmed biochemically. Significance levels $\left({ }^{*} \mathrm{p}<0.01 ;{ }^{* *} \mathrm{p}<0.001\right)$ represent comparisons with predrug baseline (Parrott et al. [64]).

\section{Psychobiological Functions Affected by Cortisol}

In an extensive review, Herbert et al. [78] noted that cortisol was important for many aspects of central nervous system integrity. The psychobiological functions affected by corticosteroids included memory, cognition, appetite, sleep, psychiatric well-being and neuronal death. 
With reference to cognition, Nagaraja et al. [89] noted that 'it is well known that cortisol may suppress hippocampal activation and impair cognitive processes'. Its influence is however often indirect, being modulated through co-factors such as heat, psychosocial stress, circadian rhythm and age. Backhaus et al. [90] found that high cortisol levels in the night were associated with impaired declarative memory scores in the morning. McEwan [91] noted that sleep deprivation adversely affected cortisol functioning, increased oxidative stress, and impaired memory and other psychobiological functions. Wolf et al. [92] found in middle-aged and elderly individuals that high baseline cortisol levels were associated with more subjective complains of memory problems. McMorris et al. [93] noted that heat stress led to significant increases in cortisol and serotonin, and concomitant deficits in a central executive processing task. Oei et al. [94] showed that psychosocial stress in young healthy males caused performance impairments on the Sternberg working memory task, with high cortisol levels being associated with these selective deficits in memory and recall. Herbert et al. [78] reviewed many similar findings but also noted:

Defining corticosteroid-related damage to the brain is not always straightforward. It may seem evident that increased neuronal death, whether precipitated directly by corticosteroids or more indirectly by their potentiating other damaging events, is disadvantageous. Decreased cognitive abilities may sometimes be directly related to corresponding diminished volumes in relevant parts of the brain (e.g. the hippocampus). In other cases, the underlying neural processes responsible for corticosteroid-dependent changes in learning or mood are not yet known and have to be inferred. Furthermore, it is not always obvious whether some of these functional effects are adaptive (i.e. advantageous). Nevertheless the literature is clear: across a wide range of data, excess corticosteroids can damage the brain or impede its function either directly, or by increasing its susceptibility to other, coincident damaging agents' (my italics).

Cortisol is also associated with psychiatric distress, since HPA activity is important for psychobiological integrity. Strohle and Holsbeer [95] noted that early life stressors can have chronic effects on HPA axis activity, and this may make the individual more susceptible to clinical abreactions - when faced with psychosocial stressors. Nemeroff and Vale [96] similarly noted:

Stressful or traumatic events occurring in early life significantly increase the risk for depression and other psychiatric illnesses in adulthood. Neural circuits containing corticotropin-releasing factor (CRF) have been identified as an important mediator of the stress response. Early-life adversity ... results in long-lasting changes in the CRF-mediated stress response and a greatly increased risk of depression in genetically predisposed persons.
Psychiatric distress has often been reported in studies of recreational ecstasy/MDMA users, and there has been extensive debate over the direction of causation $[36,40$, $43,46-48,58,59]$. Clinical reactions to ecstasy/MDMA have also been debated using the diathesis stress model; this predicts that 'drug-abreactions will develop most readily in those with the most susceptible premorbid profiles' [53]. MacInnes et al. [36] debated their finding of heightened depression in some ecstasy users applying a vulnerability model, where prior predisposition made some individuals more susceptible to drug abreactions. Soar et al. [47] noted that prior predisposition factors and intensive ecstasy usage patterns could both influence the clinical outcome. Butler and Montgomery [97] suggested that impulsivity was a personality factor of those predisposed to taking illicit drugs, but that regular MDMA usage then intensified this characteristic, possibly via serotonergic neurotoxicity. Cortisol may be another mediating factor - given the association between cortisol and impulsivity [98]. MacInnes et al. [36] found that 'intensity of ecstasy usage over 12 hours' and 'life stressors' were each associated with significantly greater depression in recreational ecstasy users. This provides another link with cortisol and vulnerability to stressors. Pacifici et al. [42] noted that the recreational MDMA prospectively led to reduced immunocompetence; again cortisol may have had a contributory role through the HPA axis. Finally, Lovallo [99] has debated the role of cortisol and HPA axis activity for many other recreational drugs.

\section{Cortisol and the Bioenergetic Stress Model of MDMA}

Cortisol may provide a unifying factor for the bioenergetic stress model of MDMA. In particular, it may help explain how the drug and nondrug stimulant factors are functionally integrated $[7,10,53,71]$. In essence, a series of integrative processes is hypothesized (table 1). Firstly, MDMA increases corticotropin-releasing factor (CRF) and by this cortisol release, and this helps increase the energetic resources available for dancing; hence the strong association between MDMA and dancing $[4,100]$, with $94 \%$ of ecstasy users reporting that they dance when on MDMA [44]. Secondly, physical activity stimulates cortisol release. Davis et al. [101] investigated 'exercise to exhaustion' on a laboratory cycling machine. The cortisol levels rose significantly after exercise, with experienced athletes showing a 78\% increase in cortisol and normal volunteers demonstrating a $138 \%$ increase in cortisol 
Table 1. Acute ecstasy/MDMA and cortisol: neuroendocrine aspects of bioenergetic stress in recreational ecstasy users

\begin{tabular}{ll}
\hline $\begin{array}{l}\text { MDMA } \\
\text { in } \\
\text { sedentary }\end{array}$ & $\begin{array}{l}\text { MDMA in the laboratory increases cortisol release. } \\
\text { This increases metabolic activation and may en- } \\
\text { hance the mood effects of the increased serotonin } \\
\text { and dopamine released by MDMA. }\end{array}$ \\
\hline $\begin{array}{l}\text { Dancing } \\
\text { in }\end{array}$ & $\begin{array}{l}\text { Physical activity and exertion can stimulate mild } \\
\text { nondrug }\end{array}$ \\
users & $\begin{array}{l}\text { HPA axis activation and cortisol release. Feedback } \\
\text { loops signal tiredness and rest breaks are taken. }\end{array}$ \\
& $\begin{array}{l}\text { Hence normal dancing is essentially non-stressful. } \\
\text { Strenuous dancing may comprise a mild metabolic } \\
\text { stressor. Prolonged exertion (e.g. marathon run- } \\
\text { ning) can be a strong metabolic stressor. }\end{array}$
\end{tabular}

MDMA MDMA induces cortisol release and hence proin vides the energy reserves for prolonged dancing. active Dancing then increases this HPA activation furdancers ther - leading to continued cortisol release. Stimulant drug plus physical activation may therefore have synergistic effects. The combination can induce intense sympathomimetic activation, strong serotonin-dopamine release and powerful mood activation.

MDMA Continued dancing with further MDMA self-dosin ing will prolong the 'desired' clubbing experience. prolonged However this will be achieved at the expense of yet dancers further acute metabolic stress. Potential dangers include metabolic overstimulation, physical exhaustion and overheating. Neural overactivity and/or neurotoxicity may be exacerbated. Psychobiological recovery problems will also be stronger.

Other Potential factors include loud and prolonged muenviron- sic, dynamic light shows, closely packed crowds, mental psychosocial and sexual stimulation, and thermal co-stimulants stress. Some users may seek out hot thermal environments to maintain the acute drug experience.

Stimulant Other central nervous system stimulants such as co-drugs amphetamine or cocaine may add to further cortisol release, and so heighten acute bioenergetic stress through synergistic neurohormonal-neurotransmitter activation.

(note: the acute cortisol release may explain why physical activity and sports are inherently pleasurable). Thirdly, the combination of stimulant drug and physical activity leads to very high levels of HPA activation - with an $800 \%$ cortisol increase in MDMA dance clubbers and party goers (table 1). Fourthly, continued cortisol release may help maintain the rewarding effects of MDMA so that MDMA users typically dance for long periods and often repeat self-dosing over the whole night $[102,103]$. Fifthly, envi- ronmental co-stimulatory factors may further enhance the acute drug response. Most sensory modalities are stimulated at dance clubs and parties (table 1), with high volumes of music, dynamic light shows $[9,71]$ and ambient temperatures increasing over the night [104, see fig. 2 in 64]. MDMA can also increase the body temperature in humans, both in the laboratory $[105,106]$ and at parties/ clubs $[85,107]$, with most recreational users feeling hot $[64,108]$. Crowding together, touching and hugging, are commonplace and may be further contributory factors. In animals cortisol is associated with mate selection and pecking order, and in humans cortisol is related to 'marital satisfaction' [109]. Cortisol may contribute to the enhanced psychosocial and psychosexual feelings of dance clubbers [66, 110].

The neurohormonal effects of cortisol are probably modulated via neurotransmission. Harris et al. [84] suggested that 'corticosteroids themselves may modulate response to drugs with potential for abuse through their effects on neurotransmitters, such as dopamine [111] and serotonin [review: 112].' Harris et al. [84] noted how cortisol could intensify the rewarding properties of psychoactive drugs, given the positive correlation between cortisol and self-rated drug liking. They noted that their human findings were consistent with the animal literature, given the positive association between corticosterone and intracranial self-stimulation [113]. In laboratory animals, high ambient temperature can also boost MDMA-related Fos gene expression [114]. Hence there are many potential co-factors for these interactive effects. In chronic terms, recreational ecstasy/MDMA users often show a range of psychobiological deficits, in memory, cognition, sleep, sex and psychiatric symptoms, and general well-being [53]. Many of these same functions are modulated by cortisol in nondrug users [78]. Hence a core hypothesis is that the chronic psychobiological effects of MDMA are partially modulated through cortisol. The core prediction is that the chronic effects of regular MDMA will reflect the cumulative experience of many acute bioenergetic stress episodes (table 2). All the drug and nondrug factors which contribute to acute cortisol release will add to the longer-term psychobiological problems.

\section{Overview}

Herbert et al. [78] noted that: 'corticosteroids are an essential component of the body's homeostatic system'. MDMA stimulates the release of cortisol in laboratory conditions [84], while in dance clubs the increase is even 
Table 2. Chronic ecstasy/MDMA and cortisol: effects on psychobiological functioning

\begin{tabular}{lll}
\hline Psychobiological function & Cortisol & MDMA/ecstasy \\
\hline $\begin{array}{l}\text { Memory: task performance deficits } \\
\text { Memory: subjective complaints }\end{array}$ & Backhaus et al. [90], 2006 & Krystal et al. [18], 1992 \\
Higher cognition: performance deficits & Molf et al. [92], 2005 & Rodgers et al. [26], 2003 \\
Other cognitive task impairments & Oei et al. [94], 2006 & Fox et al. [34], 2002 \\
Sleep and circadian rhythm deficits & Buijs et al. [80], 2006 & McCardle et al. [39], 2004 \\
Eating and feeding deficits & Nieuwenhuizen and Rutters & Mc Cann and Ricaurte [38], 2007 \\
& Turner et al. [51], 1998 \\
Heightened depression & Nemeroff and Vale [96], 2005 & MacInnes et al. [36], 2001 \\
Greater impulsivity & Fishbein et al. [98], 1989 & Butler and Montgomery [97], 2004 \\
Other clinical disorders & Strohle and Holsboer [95], 2003 & Parrott [5], 2000 \\
Oxidative stress & McEwan [96], 2006 & Zhou et al. [52], 2003 \\
Hippocampal changes & Nagaraja et al. [89], 2007 & Jacobsen et al. [121], 2004 \\
Neuronal damage & Herbert et al. [78], 2007 & Reneman et al. [15], 2006 \\
\hline
\end{tabular}

more marked (fig. 1). Hence recreational users experience profound changes in psychophysiological 'homeostatic status', generally at night when they would normally be asleep. MDMA is thus a powerful acute metabolic stressor, especially when taken under stimulating environmental conditions. Cortisol may be an integrative factor for this acute bioenergetic stress (table 1). In chronic terms, it may also contribute to the psychobiological effects of repeated ecstasy/MDMA. Herbert et al. [78] noted that the regular experience of reactive stress was cumulatively damaging to the organism, citing Selye's [74] classic studies. The bioenergetic stress model for recreational ecstasy similarly proposes that regular periods of reactive stress will be cumulatively damaging to the organism. In an earlier article I [53] suggested:

When used at low intermittent doses, while resting quietly, in low temperature conditions, with sedative or hypothermic codrugs, MDMA will lead to low rates of neuropsychobiological problems. Whereas when used intensively and repeatedly, with other CNS stimulants as co-drugs, in hot thermal environments, with prolonged physical exercise, MDMA will lead to high rates of psychobiological problems. Dances and raves may help to boost the acute effects of ecstasy/MDMA. But this may also make them more problematic in the longer term.

These multiple influences may be linked through the common factor of metabolic activation and cortisol release (table 1). Hence the bioenergetic stress model can be simplified by proposing that any factors which increase cortisol release will heighten the effects of acute MDMA and so increase the cumulative damage of repeated ecstasy usage.
This bioenergetic stress model generates many topics for future investigation. One prediction is that the strength of the acute psychobiological response to MDMA is related to the extent of the cortisol increase. These cortisol effects may also be modulated through factors such as age, gender, personality and psychiatric predisposition. All these predictions can be empirically tested. Other areas for study involve the relationship between cortisol and serotonin [112], the roles of CRF and adrenocorticotropin, and other elements of HPA circuitry [74-78]. For instance, the endogenous opiod system has links with the HPA axis and may also be important for some of the psychobiological changes - for instance the more hedonistic aspects [103]. In neurocognitive terms, Sousa and Almeida [115] noted that the effects of corticosteroids as 'sculptors of the hippocampal formation' were reversible. If cortisol is involved in the memory and cognitive effects of recreational ecstasy, then these functions may partially recover once MDMA usage had ceased. This model is different to the classic neurotoxicity model, where enduring structural deficits are hypothesized. Herbert et al. [78] noted that although most changes in cortisol were detrimental, they were sometimes beneficial. In a similar way, while many ecstasy/MDMA users report psychobiological problems $[23,26]$, benefits are also mentioned $[116,117]$. In an Internet investigation of 200 ecstasy users, the self-reported gains included a more positive outlook on life and being more open-minded. These were however balanced by reports of negative changes - including greater anxiety and heightened depression [66]. The variation in these subjective responses may be related to differences in baseline cortisol or cortisol reactiv- 
ity. For instance, changes in cortisol may make some individuals less susceptible to stress, whereas in others they may become more susceptible to anxiety and depression. These changes may also be related to lifetime usage, since most novice users report few problems, while heavy users often complain of multiple problems [23, 50]. It may be that any cortisol changes are comparatively mild in novice users but stronger and more biologically disruptive in heavier users. Cortisol may particularly influence specific psychobiological functions. For instance, those involving high energy expenditure or where neurohormonal activity is particularly important. However since cortisol is crucial for basic homeostasis [74-78], it is difficult to predict any psychobiological functions where it will not be involved.

Cortisol is just one of several potentially important neurohormones. Dumont and Verkes [81] noted that prolactin, luteinizing hormone, oestradiol, follicle-stimulating hormone, progesterone and growth hormone had each been investigated in human volunteers, mostly in single studies [42, 82, 84]. More recently testosterone has also been studied [64: see fig. 1]. In laboratory animals, the 'social neuropeptide' oxytocin contributes to the reinforcing effects of MDMA [118], and it may be impor- tant for humans. For instance, oxytocin administration improves recognition memory for human faces, although not for nonsocial stimuli [123]. Hence any chronic changes in oxytocin might be related to the amnesic aspects of MDMA or its effects on social intelligence [28]. Most hormone levels are acutely increased by MDMA (fig. 1), but there are very few data on chronic changes. These neurohormonal modifications will also be linked through overlapping HPA pathways, so it will often be difficult to associate specific neurohormones with particular functions. The hypothalamic-pituitary-gonadal axis should also be important. Finally, the bioenergetic stress model can be applied to all the recreational dance drugs (table 1). Cortisol may be an important modulatory factor for amphetamine, cocaine and methamphetamine - as well as MDMA.

\section{Acknowledgements}

The preparatory research and writing were facilitated by grant RO1-DA-14910-01 of the National Institute on Drug Abuse. The core of this article was first presented at the Annual Conference of the British Association for Psychopharmacology, in July 2007 [119].

\section{References}

1 Green AR, Mechan AO, Elliott JM, O'Shea E, Colado MI: The pharmacology and clinical pharmacology of 3,4-methylenedioxymethamphetamine (MDMA, 'ecstasy'). Pharmacol Rev 2003;55:463-508.

-2 Ricaurte GA, Bryan G, Strauss L, Seiden LS, Schuster CR: Hallucinogenic amphetamine selectively destroys brain serotonin nerve terminals. Science 1985;229:986-988.

-3 Ricaurte GA, Yuan J, McCann UD: ( \pm ) 3,4methylenedioxymethamphetamine (MDMA, 'Ecstasy')-induced serotonin neurotoxicity: studies in animals. Neuropsychobiology 2000;42:5-10.

4 Cohen RS: The Love Drug: Marching to the Beat of Ecstasy. New York, Haworth Medical Press, 1998

5 Parrott AC: Human research on MDMA (3,4-methylenedioxymethamphetamine) neurotoxicity: cognitive and behavioural indices of change. Neuropsychobiology 2000; 42:17-24.

6 Schifano F: Potential human neurotoxicity of MDMA ('Ecstasy'): subjective self-reports, evidence form an Italian drug addiction centre and clinical case studies. Neuropsychobiology 2000;42:25-33.

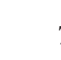

7 Parrott AC: Recreational Ecstasy/MDMA, the serotonin syndrome, and serotonergic neurotoxicity. Pharmacol Biochem Behav 2002;71:837-844.

-8 Schifano F, Corkery J, Deluca P, Oyefeso A, Ghodse AH: Ecstasy (MDMA, MDA, MDEA, MBDB) consumption, seizures, related offences, prices, dosage levels and deaths in the UK (1994-2003). J Psychopharmacol 2006; 20:456-463.

-9 Suy K, Gijsenbergh F, Baute L: Emergency medical assistance during a mass gathering. Eur J Emerg Med 1999;6:249-254.

10 Huether G, Zhou D, Ryuther E: Causes and consequences of the loss of serotonergic presynapses elicited by the consumption of 3,4 methylenedioxymethamphetamine (MDMA, 'ecstasy') and its congeners. J Neural Transm 1997;104:771-794.

11 Malberg JE, Seiden LS: Small changes in ambient temperature cause large changes in 3,4methylenedioxymethamphetamine (MDMA)- induced serotonin neurotoxicity and core body temperature in the rat. J Neurosci 1998;18:5086-5094.
12 Sanchez V, O'Shea E, Saadat KS, Elliott JM, Colado MI, Green AR: Effect of repeated ('binge') dosing of MDMA to rats housed at normal and high temperature on neurotoxic damage to cerebral 5-HT and dopamine neurones. J Psychopharmacol 2004; 18:412416.

13 Cowan RL: Neuroimaging research in human MDMA users: a review. Psychopharmacology 2007;189:539-556.

14 Eastern N, Marsden CA: Ecstasy: are animal data consistent between species and can they translate to humans? J Psychopharmacol 2006;20:194-210.

15 Reneman L, de Win MM, van den Brink W, Booij J, den Heeten GJ: Neuroimaging findings with MDMA/ecstasy: technical aspects, conceptual issues and future prospects. J Psychopharmacol 2006;20:164-175.

16 Thomasius R, Petersen K, Buchert R, Andresen B, Zapletalova P, Wartberg L, Nebeling B, Schmoldt A: Mood, cognition and serotonin transporter availability in current and former ecstasy (MDMA) users. Psychopharmacology 2003;167:85-96. 
-17 Thomasius R, Zapletalova P, Petersen K, Buchert R, Andresen B, Wartberg L, Nebeling B, Schmoldt A: Mood, cognition and serotonin transporter availability in current and former ecstasy (MDMA) users: the longitudinal perspective. J Psychopharmacol 2006; 20:211-225

-18 Krystal JH, Price LH, Opsahl C, Ricaurte GA, Heninger GR: Chronic 3,4-methylenedioxymethamphetamine (MDMA) use: effects on mood and neuropsychological function? Am J Drug Alcohol Abuse 1992;18: 331-341.

-19 Fox H, Parrott AC, Turner JJD: Ecstasy/ MDMA-related cognitive deficits: a function of dosage rather than awareness of problems. J Psychopharmacol 2001;15:273-281.

-20 Gouzoulis-Mayfrank E, Daumann J, Tuchtenhagen F, Pelz S, Becker S, Kunert HJ, Fimm B, Sass H: Impaired cognitive performance in drug-free recreational ecstasy (MDMA) users. J Neurol Neurosurg Psychiatry 2000;68:719-725.

-21 Morgan MJ: Memory deficits associated with recreational use of 'ecstasy' (MDMA). Psychopharmacology 1999;141:30-36.

-22 Parrott AC, Lees A, Garnham NJ, Jones M, Wesnes K: Cognitive performance in recreational users of MDMA or 'ecstasy': evidence for memory deficits. J Psychopharmacol 1998;12:79-83.

-23 Parrott AC, Buchanan T, Scholey AB, Heffernan TM, Ling J, Rodgers J: Ecstasy-attributed problems reported by novice, moderate and heavy recreational users. Hum Psychopharmacol 2002;17:309-312.

24 Parrott AC, Lasky J: Ecstasy (MDMA) effects upon mood and cognition; before, during, and after a Saturday night dance. Psychopharmacology 1998;139:261-268.

25 Rodgers J: Cognitive performance amongst recreational users of 'ecstasy'. Psychopharmacology 2000;151:19-24.

-26 Rodgers J, Buchanan T, Scholey AB, Heffernan TM, Ling J, Parrott AC: Patterns of drug use and the influence of gender on self-reports of memory ability in ecstasy users: a web-based study. J Psychopharmacol 2003; 17:379-386

-27 Verkes RJ, Gigsman HJ, Pieters MSM, Schoemaker RC, de Visser S, Kuijpers M: Cognitive performance and serotonergic function in users of Ecstasy. Psychopharmacology 2001;53:196-202.

$\checkmark 28$ Reay JL, Hamilton C, Kennedy DO, Scholey AB: MDMA polydrug users show processspecific central executive impairments coupled with impaired social and emotional judgement processes. J Psychopharmacol 2006;20:385-388.

-29 Wareing M, Fisk M, Murphy JE: Working deficits in current and previous users of MDMA ('ecstasy'). Br J Psychol 2000;91:181188 .
30 Wareing M, Murphy PN, Fisk JE: Visuospatial memory impairments in users of MDMA ('ecstasy'). Psychopharmacology 2004;173: 391-397.

31 Zakzanis KK, Young DA: Memory impairment in abstinent MDMA ('ecstasy') users: a longitudinal investigation. Neurology 2001; 56:966-969.

32 Zakzanis KK, Campbell Z: Memory impairment in now abstinent MDMA users and continued users: a longitudinal follow-up Neurology 2006;66:740-741.

33 Fisk JE, Montgomery C, Wareing M, Murphy PN: Reasoning deficits in ecstasy (MDMA) polydrug users. Psychopharmacology 2005; 181:550-559.

34 Fox HC, McLean A, Turner JJD, Parrott AC, Rogers R, Sahakian BJ: Neuropsychological evidence of a relatively selective profile of temporal dysfunction in drug-free MDMA ('ecstasy') polydrug users. Psychopharmacology 2002;162:203-214.

35 Halpern JH, Pope HG, Sherwood AR, Barry S, Hudson JI, Yurgelun-Todd D: Residual effects of illicit 3,4-methylenedioxymethamphetamine in individuals with minimal exposure to other drugs. Drug Alcohol Depend 2004;75:135-147.

36 MacInnes N, Handley SL, Harding GFA: Former chronic methylenedioxymethamphetamine (MDMA or ecstasy) users report mild depressive symptoms. J Psychopharmacol 2001;15:181-186.

37 McCann UD, Eligulashvili V, Ricaurte GA: 3,4-MDMA ('Ecstasy')-induced serotonin neurotoxicity: clinical studies. Neuropsychobiology 2000;42:11-16.

38 McCann UD, Ricaurte GA: Effects of $(+/-)$ 3,4-methylenedioxymethamphetamine (MDMA) on sleep and circadian rhythms. Sci World J 2007;2:231-238.

39 McCardle K, Luebbers S, Carter JD, Croft RJ Stough C: Chronic MDMA (ecstasy) use cognition and mood. Psychopharmacology 2004;173:434-439.

40 Milani RM, Parrott AC, Schifano F, Turner JJ: Pattern of cannabis use in ecstasy polydrug users: moderate cannabis use may compensate for self-rated aggression and somatic symptoms. Hum Psychopharmacol 2005;20: 240-261.

41 Pacifici R, Zuccaro P, Farre M, Pichini S, D Carlo S, Roset PN, Ortuno J, Segura J, de la Torre R: Immunomodulating properties of MDMA alone and in combination with alcohol: a pilot study. Life Sci 1999;65:309-316.

42 Pacifici R, Zuccaro P, Farre M, Pichini S, D Carlo S, Roset PN, Ortuno J, Pujadas M, Bacosi A, Menoyo E, Segura J, de la Torre R: Effects of repeated doses of MDMA ('ecstasy') on cell-mediated immune response in humans. Life Sci 2001;69:2931-2941.

43 Parrott AC, Milani R, Parmar R, Turner JJD: Ecstasy polydrug users and other recreational drug users in Britain and Italy: psychiatric symptoms and psychobiological problems. Psychopharmacology 2001;159:77-82.
44 Parrott AC, Rodgers J, Buchanan T, Ling J, Heffernan T, Scholey AB: Dancing hot on ecstasy: physical activity and thermal comfort ratings are associated with the memory and other psychobiological problems of recreational MDMA users. Hum Psychopharmacol 2006;21:285-298.

45 Quednow BB, Kuhn KU, Hoenig K, Maier W, Wagner M: Prepulse inhibition and habituation of acoustic startle response in male MDMA ('Ecstasy') users, cannabis users, and healthy controls. Neuropsychopharmacology 2004;29:982-990.

46 Roiser JP, Sahakian BJ: Relationship between ecstasy use and depression: a study controlling for poly-drug use. Psychopharmacology 2004;173:411-417.

47 Soar K, Turner JJD, Parrott AC: Psychiatric disorders in recreational Ecstasy (MDMA) users: a literature review focusing upon personal predisposition factors and drug histories. Hum Psychopharmacol 2001;16:641646 .

48 Soar K, Parrott AC, Turner JJD: Persistent neuropsychological problems after seven years of abstinence from recreational Ecstasy (MDMA): a case study. Psychol Rep 2004; 95:192-196.

49 Soar K, Parrott AC, Turner JJD: No more the 'love drug': sexual behaviour impairments in Ecstasy users. J Psychopharmacol 2005;19: a25.

50 Topp L, Hando J, Dillon P, Roche A, Solowij $\mathrm{N}$ : Ecstasy use in Australia: patterns of use and associated harm. Drug Alcohol Depend 1999;55:105-115.

51 Turner JJD, Nicolas L, Parrott AC: Reduced calorie intake in the week following weekend MDMA (ecstasy) use. J Psychopharmacol 1998;12:a43.

-52 Zhou JF, Chen P, Zhou YH, Zhang L, Chen $\mathrm{HH}$ : 3,4-methylenedioxymethamphetamine abuse may cause oxidative stress and potential free radical damage. Free Radic Res 2003; 37:491-497

53 Parrott AC: MDMA in humans: factors which affect the neuropsychobiological profiles of recreational Ecstasy users, the integrative role of bio-energetic stress. J Psychopharmacol 2006;20:147-163

54 Back-Madruga C, Boone KB, Chang L, Grob CS, Lee A, Nations H, Poland RE: Neuropsychological effects of 3,4-methylenedioxymethamphetamine (MDMA or ecstasy) in recreational users. Clin Neuropsychol 2003; 17:446-459.

55 Jansen KLR: Ecstasy (MDMA) dependence. Drug Alcohol Depend 1999;53:121-124.

56 Schilt T, de Win MM, Koeter M, Jager G, Korf DJ, van den Brink W, Schmand B: Cognition in novice ecstasy users with minimal exposure to other drugs: a prospective cohort study. Arch Gen Psychiatry 2007;64: 728-736 
57 Mejias S, Rossignol M, Debatisse D, Streel E, Servais L, Guerit JM, Philippot P, Campanella S: Event-related potentials in ecstasy (MDMA) users during a visual oddball task. Biol Psychol 2005;69:333-352.

58 Parrott AC, Sisk E, Turner J: Psychobiological problems in heavy 'ecstasy' (MDMA) polydrug users. Drug Alcohol Depend 2000; 60:105-110.

-59 Schifano F, DiFuria L, Forza G, Minicuci N, Bricolo R: MDMA consumption in the context of polydrug abuse: a report on $150 \mathrm{pa}-$ tients. Drug Alc Depend 1998;52:85-90.

60 Clemens KJ, McGregor IS, Hunt GE, Cornish JL: MDMA, methamphetamine and their combination: possible lessons for party drug users from recent preclinical research. Drug Alcohol Rev 2007;26:9-15.

-61 Croft RJ, Mackay AJ, Mills ATD, Gruzelier JGH: Electrophysiological evidence of serotonergic impairment in long-term MDMA ('Ecstasy') users. Am J Psychiatry 2001;158: 1687-1692.

62 Morgan MJ, McFie L, Fleetwood LH, Robinson JA: Ecstasy (MDMA): are the psychological problems associated with its use reversed by prolonged abstinence? Psychopharmacology 2002;159:294-303.

63 Parrott A, Morinan A, Moss M, Scholey A: Understanding Drugs and Behaviour. Chichester, Wiley, 2004.

64 Parrott AC, Lock J, Conner AC, Kissling C, Thome J: Dance clubbing on MDMA and during abstinence from Ecstasy/MDMA: prospective neuroendocrine and psychobiological changes. Neuropsychobiology 2008; 57:165-180.

65 Ramaekers JG, Kuypers KP: Acute effects of 3,4-methylenedioxymethamphetamine (MDMA) on behavioral measures of impulsivity: alone and in combination with alcohol. Neuropsychopharmacology 2006;31: 1048-1055.

66 Rodgers J, Buchanan T, Pearson C, Parrott AC, Ling J, Hefferman TM, Scholey AB: Differential experiences of the psychobiological sequelae of ecstasy use: quantitative and qualitative data from an internet study. J Psychopharmacol 2006;20:437-446.

67 Sala M, Braida D: Endocannabinoids and 3,4-methylenedioxymethamphetamine (MDMA) interaction. Pharmacol Biochem Behav 2005;81:407-416.

68 Scholey AB, Parrott AC, Buchanan T, Heffernan T, Ling J, Rodgers J: Increased intensity of ecstasy and polydrug usage in the more experienced recreational ecstasy/ MDMA users: a www study. Addict Behav 2004;29:743-752.

69 Parrott AC, Milani RM, Gouzoulis-Mayfrank E, Daumann J: Cannabis and Ecstasy/ MDMA (3,4-methylenedioxymethamphetamine): an analysis of their neuropsychobiological interactions in recreational users. J Neural Transm 2007a;114:959-968.
70 Rizzo M, Lamers CTJ, Sauer CG, Ramaekers JG, Bechara A, Anderson GJ: Impaired perception of self-motion (heading) in abstinent ecstasy and marijuana users. Psychopharmacology 2005;179:559-566.

71 Parrott AC: MDMA (3,4-methylenedioxymethamphetamine) or Ecstasy: the neuropsychobiological implications of taking it at dances and raves. Neuropsychobiology 2004 50:329-335.

72 Silins E, Copeland J, Dillon P: Qualitative review of serotonin syndrome, ecstasy (MDMA) and the use of other serotonergic substances: hierarchy of risk. Aust NZ J Psychiatry 2007;41:649-655.

73 Darvesh AS, Gudelsky GA: Evidence for a role of energy dysregulation in the MDMAinduced depletion of brain 5-HT. Brain Res 2005;21:168-175.

74 Selye H: The Stress of Life. New York, McGraw Hill, 1956.

75 Lovallo WR: Stress and Health: Biological and Psychological Interactions. Thousand Oaks, Sage, 1997.

76 Cannon WB: Stresses and strains of homeostasis. Am J Med Sci 1935;189:1-14.

77 Munck A, Guyre PM, Holbrook NJ: Physiological functions of glucocorticoids in stress and their relation to pharmacological actions. Endocr Rev 1984;5:25-44.

78 Herbert J, Goodyer IM, Grossman AB, Hastings MH, de Kloet ER, Lightman SL, Lupien SJ, Roozendaal B, Seckl JR: Do corticosteroids damage the brain? J Neuroendocrinol 2006;18:393-411.

79 Halberg F: Circadian (about twenty-fourhour) rhythms in experimental medicine. Proc R Soc Med 1963;56:253-257.

80 Buijs RM, Scheer FA, Kreier F, Yi C, Bos N, Goncharuk VD, Kalsbeek A: Organization of circadian functions: interaction with the body. Prog Brain Res 2006;153:341-360.

81 Dumont GJ, Verkes RJ: A review of acute effects of 3,4-methylenedioxymethamphetamine in healthy volunteers. J Psychopharmacol 2006;20:176-187.

82 Mas M, Farre M, de la Torre R, Roset PN, Ortuno J, Segura J, Cami J: Cardiovascular and neuroendocrine effects and pharmacokinetics of 3,4-methylenedioxymethamphetamine in humans. J Pharmacol Exp Ther 1999;290:136-145.

83 De la Torre R, Farre M, Roset PN, Lopez CH, Mas M, Ortuno J, Menoyo E, Pizarro N, Segura J, Cami J: Pharmacology of MDMA in humans. Ann NY Acad Sci 2000;914:225237.

-84 Harris DS, Baggott M, Mendelson JH, Mendelson JE, Jones RT: Subjective and hormonal effects of 3,4-methylenedioxymethamphetamine (MDMA) in humans. Psychopharmacology 2002;162:396-405.

85 Parrott AC, Parrott L, Evans A, Kissling C, Thome J: Heavy Ecstasy/MDMA use at cool house parties: substantial cortisol release and increased body temperature. J Psychopharmacol 2007;21:a35.
86 Gerra G, Zaimovic A, Giucastro G, Maestri D, Monica C, Sartori R, Caccavari R, Delsignore R: Serotonergic function after (+/-) 3,4-methylene-dioxymethamphetamine ('Ecstasy') in humans. Int Clin Psychopharmacol 1998;13:1-9.

87 Gerra G, Zaimovic A, Ferri M, Zambelli U, Timpano M, Neri E, Marzocchi GF, Delsignore R, Brambilla F: Long-lasting effects of (+/-)3,4-methylenedioxymethamphetamine (ecstasy) on serotonin system function in humans. Biol Psychiatry 2000;47:127136.

88 Gerra G, Bassignana S, Zaimovic A, Moi G, Bussandri M, Caccavari C, Brambilla F: Hypothalamic-pituitary-adrenal axis responses to stress in subjects with 3,4-methylenedioxy-methamphetamine ('ecstasy') use history: correlation with dopamine receptor sensitivity. Psychiatry Res 2003;120:115124.

89 Nagaraja N, Andrade C, Sudha S, Madan Singh N, Chandra JS, Venkataraman BV: Glucocorticoid mechanisms may contribute to ECT-induced retrograde amnesia. Psychopharmacology 2007;190:73-80.

90 Backhaus J, Junghanns K, Born J, Hohaus K, Faasch F, Hohagen F: Impaired declarative memory consolidation during sleep in patients with primary insomnia: influence of sleep architecture and nocturnal cortisol release. Biol Psychiatry 2006;60:1324-1330.

91 McEwan BS: Sleep deprivation as a neurobiologic and physiologic stressor: allostasis and allostatic load. Metabolism 2006;55(suppl 2):S20-S23.

-92 Wolf OT, Dziobek I, McHugh P, Sweat V, de Leon MJ, Javier E, Convit A: Subjective memory complaints in aging are associated with elevated cortisol levels. Neurobiol Aging 2005;26:1357-1363.

93 McMorris T, Swain J, Smith M, Corbett J, Delves S, Sale C, Harris RC, Potter J: Heat stress, plasma concentrations of adrenaline, noradrenaline, 5-hydroxytryptamine and cortisol, mood state and cognitive performance. Int J Psychophysiol 2006;6:204-215.

94 Oei NY, Everaerd WT, Elzinga BM, van Well S, Bermond B: Psychosocial stress impairs working memory at high loads: an association with cortisol levels and memory retrieval. Stress 2006;9:133-141.

95 Strohle A, Holsboer F: Stress-responsive neurohormones in depression and anxiety. Pharmacopsychiatry 2003;36(suppl 3):S207S214.

96 Nemeroff CB, Vale WW: The neurobiology of depression: inroads to treatment and new drug discovery. J Clin Psychiatry 2005; 66(suppl 7):5-13.

97 Butler GKL, Montgomery AMJ: Impulsivity, risk taking and recreational 'ecstasy' (MDMA) use. Drug Alcohol Depend 2004; 76:55-62. 
98 Fishbein DH, Lozovsky D, Jaffe JH: Impulsivity, aggression, and neuroendocrine responses to serotonergic stimulation in substance abusers. Biol Psychiatry 1989;25: 1049-1066.

99 Lovallo WR: Cortisol secretion patterns in addiction and addiction risk. Int J Psychophysiol 2006;59:195-202.

100 Winstock AR, Griffiths P, Stewart D: Drugs and the dance music scene: a survey of current drug use patterns among a sample of dance music enthusiasts in the UK. Drug Alcohol Depend 2001;64:9-17

101 Davis H, Gass G, Basset J: Serum cortisol response to incremental work in experienced and naive subjects. Psychosom Med 1981;43:127-132.

102 Hammersley R, Ditton J, Smith I, Short E: Patterns of ecstasy use by drug users. Br J Criminol 1999;39:625-647.

103 Parrott AC: Chronic tolerance to recreational MDMA (3,4 methylenedioxymethamphetamine) or ecstasy. J Psychopharmacol 2005; 19:71-83.

104 Cole JC, Sumnall HR, Smith GW, RostamiHodjegan A: Preliminary evidence of the cardiovascular effects of polysubstance misuse in night clubs. J Psychopharmacol 2005;19:67-70.

105 Liechti ME, Gamma A, Vollenweider FX: Gender differences in the subjective effects of MDMA. Psychopharmacology 2001;154: 161-168.

106 Freedman FR, Johanson C, Tancer ME: Thermoregulatory effects of 3,4-methylenedioxymethamphetamine (MDMA) in humans. Psychopharmacology 2005; 183: 248-256.
107 Parrott AC, Young L: Increased body temperature in recreational Ecstasy/MDMA users out clubbing and dancing, J Psychopharmacol 2005; 19:a26.

108 Davison D, Parrott AC: Ecstasy in recreational users: self-reported psychological and physiological effects. Hum Psychopharmacol 1997;12:91-97.

109 Saxbe DE, Repetti RL, Nishina A: Marital satisfaction, recovery from work, and diurnal cortisol among men and women. Health Psychol 2008;27:15-25.

110 Parrott AC: Human psychopharmacology of Ecstasy (MDMA): a review of fifteen years of empirical research. Hum Psychopharmacol 2001;16:557-577.

111 Piazza PV, Maccari S, Deminière JM, Le Moal M, Mormède P, Simon H: Corticosterone levels determine individual vulnerability to amphetamine self-administration. Proc Natl Acad Sci USA 1991;88:20882092.

112 Chaouloff F: Serotonin, stress and corticoids. J Psychopharmacol 2000;14:139151.

113 Goeders NE, Guerin GF: Role of corticosterone in intravenous cocaine self-administration in rats. Neuroendocrinology 1996; 64:337-348.

114 Hargreaves GA, Hunt GE, Cornish JL, McGregor IS: High ambient temperature increases 3,4-methylenedioxymethamphetamine (MDMA, 'ecstasy')-induced Fos expression in a region-specific manner. Neuroscience 2007; 145:764-774.
115 Sousa N, Almeida OF: Corticosteroids: sculptors of the hippocampal formation. Rev Neurosci 2002;13:59-84

116 Greer G, Tolbert R: Subjective reports of the effects of MDMA in a clinical setting. J Psychoactive Drugs 1986;18:319-327.

117 Parrott AC: The psychotherapeutic potential of MDMA (3,4-methylenedioxymethamphetamine): an evidence-based review. Psychopharmacology 2007;191:181-193.

118 McGregor IS, Callaghan PD, Hunt GE: From ultrasocial to antisocial: a role for oxytocin in the acute reinforcing effects and long-term adverse consequences of drug use? Br J Pharmacol 2008;154:358368.

119 Parrott AC: MDMA and cortisol: neuroendocrine aspects of energetic stress in recreational ecstasy users. J Psychopharmacol 2007;21:a31.

120 Nieuwenhuizen AG, Rutters F: The hypothalamic-pituitary-adrenal-axis in the regulation of energy balance. Physiol Behav 2008;94:169-177.

121 Jacobsen LK, Mencl WE, Pugh KR, Skudlarski P, Krystal JH: Preliminary evidence of hippocampal dysfunction in adolescent MDMA ('ecstasy') users: possible relationship to neurotoxic effects. Psychopharmacology 2004;173:383-390.

122 Rendell PG, Gray TJ, Henry JD, Tolan A: Prospective memory impairment in 'ecstasy' (MDMA) users. Psychopharmacology 2007;194:497-504.

123 Rimmele U, Hediger K, Heinrichs $\mathrm{M}$, Klaver P: Oxytocin makes a face in memory familiar. J Neurosci 2009;29:38-42. 